\title{
The Platform
}

A novel non-invasive fish monitoring method

Estuary environments are incredibly variable, both spatially and temporally, which can make fish monitoring using tradition sampling gear difficult. Dr Joseph Merz, of Cramer Fish Sciences, has developed a new for this purpose The gear Platform Aquatic Species and Habitat Sampling System (or The Platform) is able to monito fish communities and their habitat interactions across various habitat types via video capture, without the need for fish handling, reducing potential impacts to sensitive species. Thi forld prove to be a useful tool impacts on ecosystopog impacts on ecosystems,
while helping inform future estuary management.

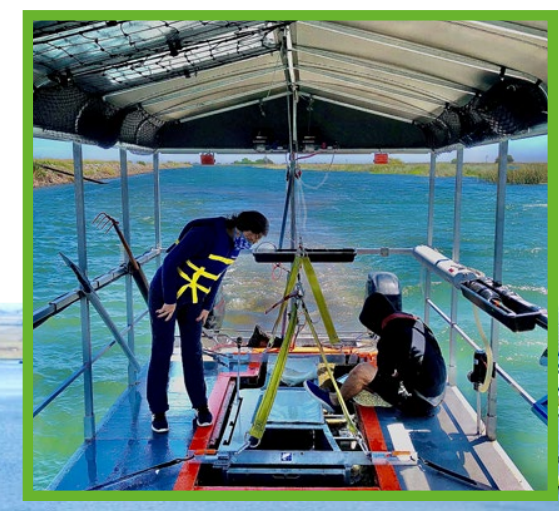

- stuaries are seasonally variable environments. As a result, the life - cycles of many organisms found estuaries have seasonal patterns of migration, growth, reproduction, and habitat associations. In recent years, there has been significant investment in restoring impaired estuaries to protect is a need to quantify chan such, there habitats, the resulting effects on aquatic organisms, and also to evaluate the success of restoration efforts.

Presently, estuary fish sampling is Habitats that can be effectively samp. with available gears tend to be sampled more intensively, while other habitats may be under-represented. Trawls are typically used to sample open water, while seines are used to sample beach and nearshore habitats. However, trawls lack manoeuvrability and can cause stress and injury to the fish, while seines are very limited in where they can effectively be deployed. As such, the methods used tom mors popula mions can lintita and compare the data collected overtin or across different sampling methods.

Dr Joseph Merz, of Cramer Fish Sciences and his team designed the SinglePlattorm Aquatic Species and Habitat Sampling System (or The Plattorm), a new and innovative tool for fish monitoring. The Platform can sample both open and shallow water, as well as complex habitats that are beyond the reach of traditional uned to methre The hough can be used to capture fis for hands-on data invasive sampling technique by passively recording fish by video.

\section{DESIGN OF THE PLATFORM}

The Platform is a modified pontoon

boat with a concentrator net attached

at its front. The sample mouth extend

in the front, while the rest of the net

passes under the boat. Water and fish are

channelled between the two pontoons,

where they pass through a removeable

Whe box mounted underneath the deck,

Because The Platform funnels fish past cameras in the live box, it reduces handling and

processing - recorded video images are nalysed after the survey. This improves
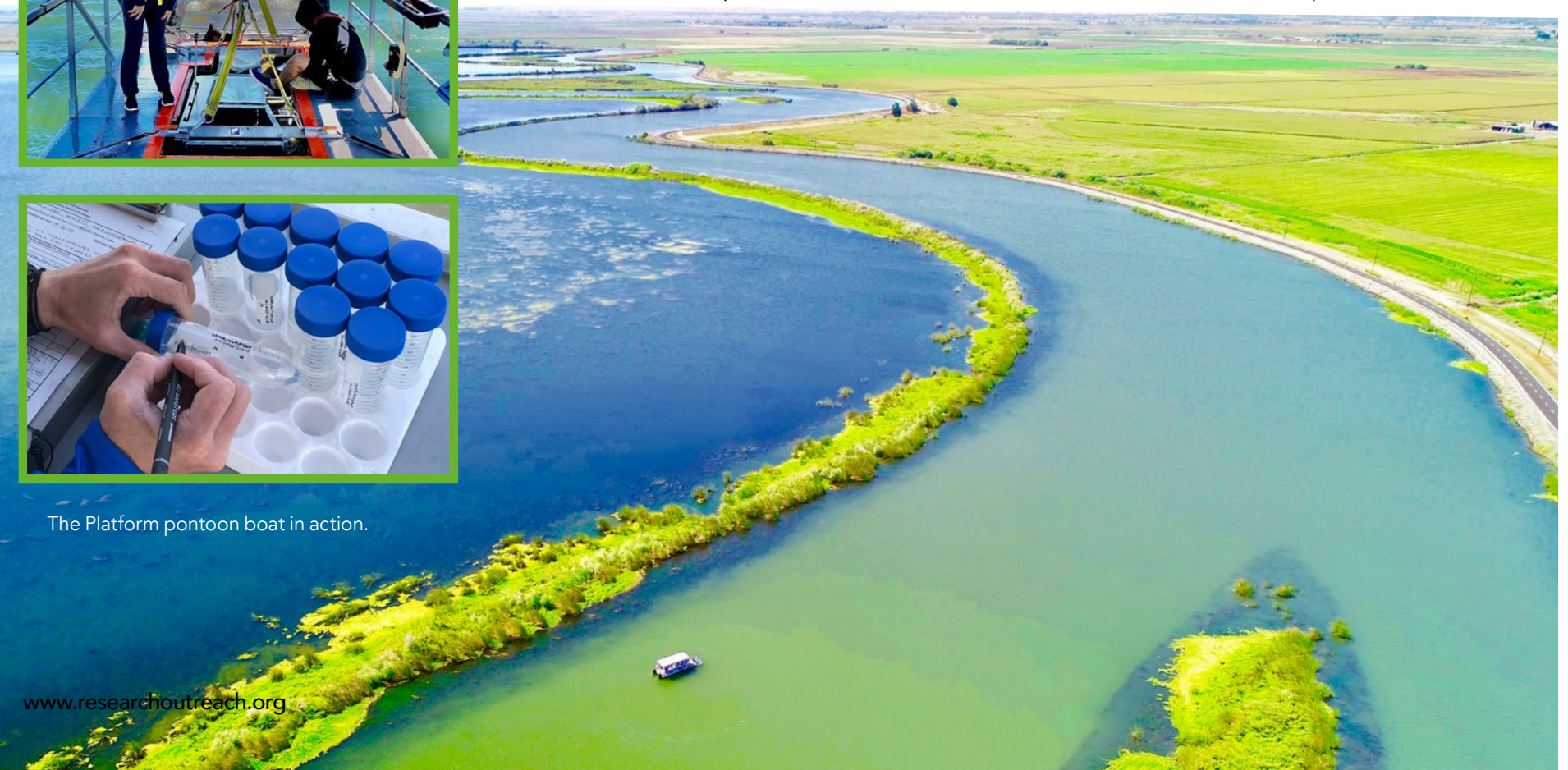

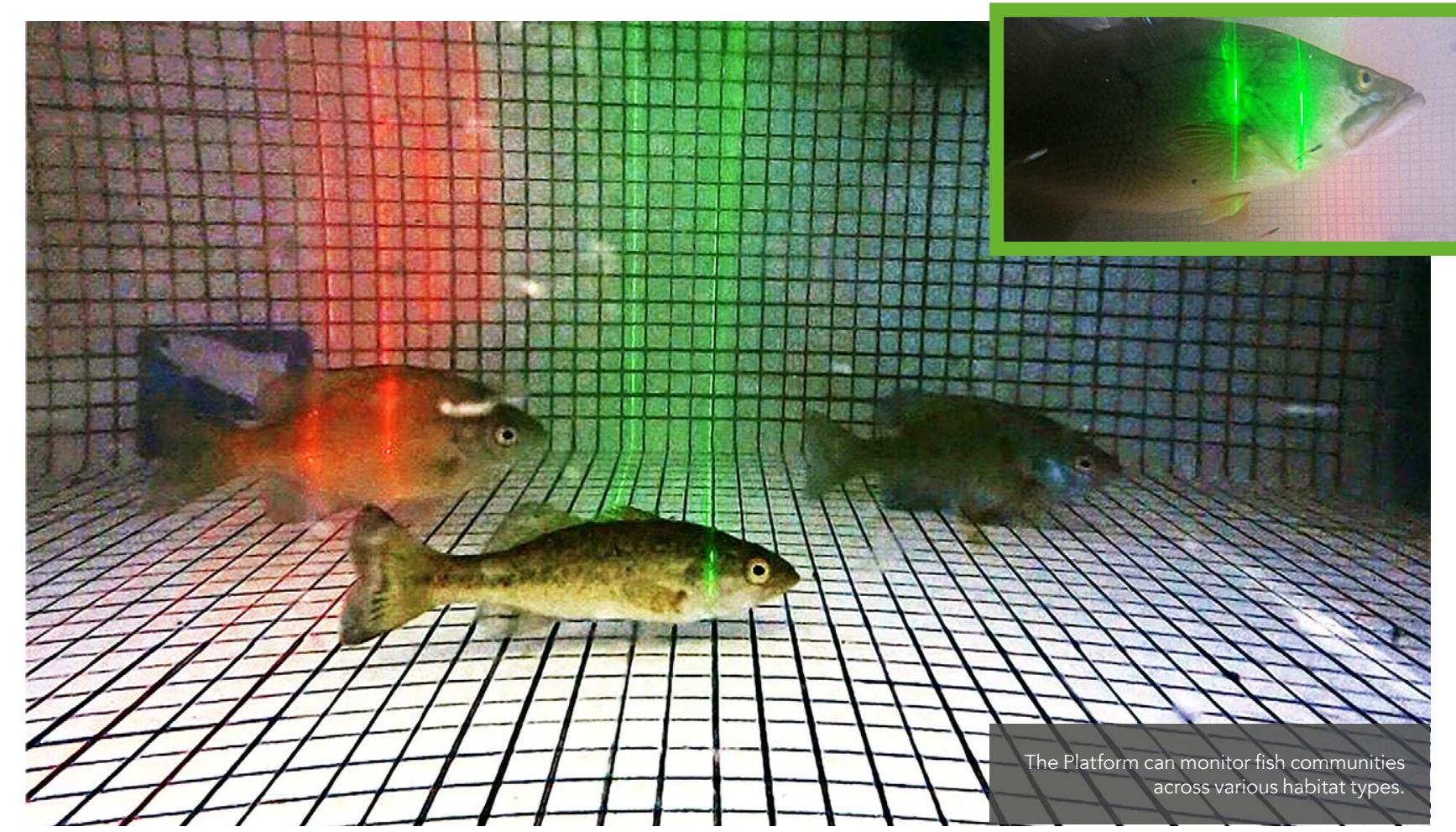

sampling efficiency across a variety of aquatic habita injury, and lethal take of sensitive fish species, enabling researchers to monitor fish communities in a relatively noninvasive way.

The Platform is also equipped with a range of physical monitoring equipment This allows a variety of biotic and abiotic data, including waterquality metrics and plankton assemblages, to be collected concurrently with fish sampling data -
something that would normally require something that
multiple surveys multiple surveys
using different methods. In this way, more standardised data are produced, with the ability to relate environmental relate environmental
conditions directly to fish observations.

THE PLATFORM IN PRACTICE team set out to test The Platform's bility to sample across different hab types and detect differences in fish communities. This would allow them to sudy the abundance and distribution of fish species across different habitats. The study was performed at Mildred San Francisco Estuary. The estuary is characterised by significant changes over the last 170 years, including the removal of $95 \%$ of the historical estuary wetlands for agricultural and industrial use, channelisation and dredging of rivers, and the removal of large woody debris. It is also considered the most invaded habitat on the planet, with large populations of non-native species that have been introduced over time.

The team identified four habitat types within the sample area: open wetland, open water wer The Platform was able to adequately
sample fish across habitat types that would normally require multiple types of gear. riverine, and riverine wetland. They performed a total of 205 transects using The Platform between 26 July and 31 August 2018. Across all transects, 24,213 fish were sampled in total, with 16 different species being identified. Of those sampled, $94 \%$ of the fish species observed were non-native, The Plattorm was successfully able to capture changes in habitat association species obsented.
The research team was able to demonstrate The Platform's ability to dentify physical distinctions among the four estuary habitats, and to detect the segregation of fish species among these habitats. The study also demonstrated hat The Platform is capable of collecting standardised environmental data Thu ancously with fish species data. This allows changes in fish communities to to be properly evaluated. Accurately efficiently monitoring changes in the nitoring changes in the ecosystem and appropriately
responding to these changes.

Through this trial of The Platform, the research team showed it to be an effective method of monitoring fish and their associated habitats. They were able to sample small-bodied fish species in a range of habitats using a single med, collecting results comparable sampling methods.

THE PLATFORM VERSUS

CONVENTIONAL SAMPLING

The Platform overcomes many of the 


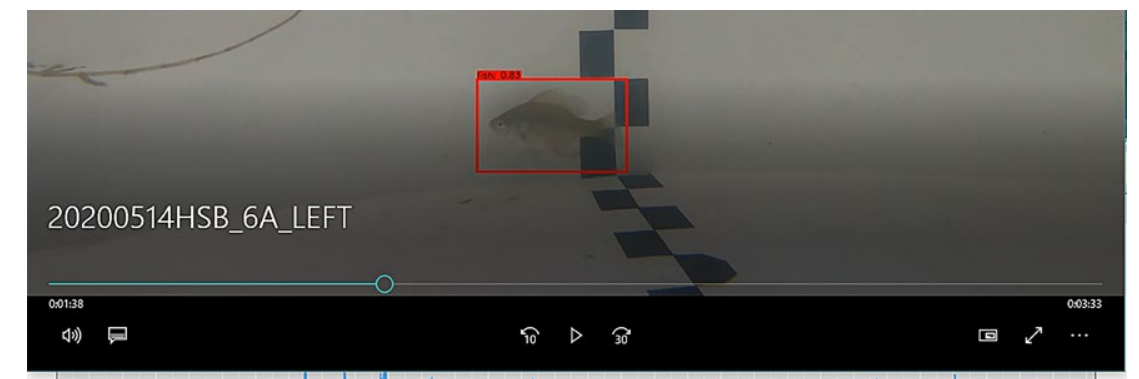

\|\|$\quad||\||\|\mid\|\|\|\|\|\|\|\|\|\|\|\|\|\|\|\|\|\|\|$

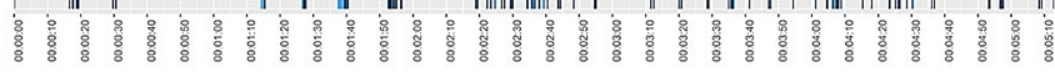
The Platform can sample fish communities and their habitat interactions
automatically detected and time-stamped for measurement and review.

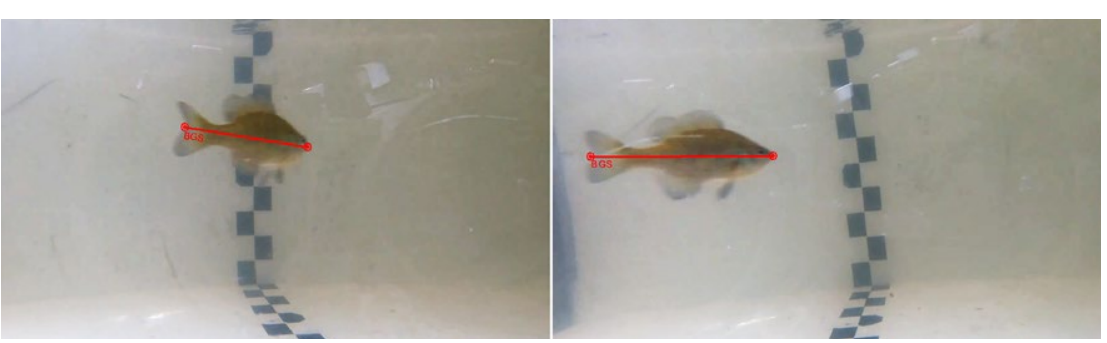

Fish are automatically detected and time-stamped. Stereoscopic cameras allow fish to be accurately measured and

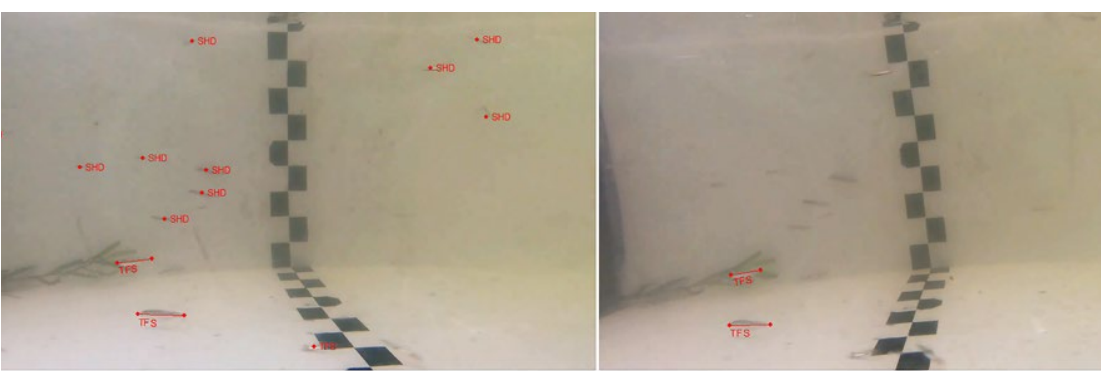

The early life stages of various fish species are often under-sampled by traditional gear.

methods used in fish monitoring. For example, seining is often limited by depth and shore access, and is only capable of sampling small water volumes per haul. Meanwhile, trawls are inefficient in comparison to other echniques, as they lack manoeuvrability and can alter the behaviour of the fish being sampled. In addition, as most conventional sampling methods requ capture and handling, they may be sociated with significant stress, injury, d mortality of the fish

For estuary environments, different sample gears are generally used at
Dr Merz and his team conducted a study comparing the performance of
The Platform against two conventional monitoring methods, beach seining vegetation, and tree branches can all provide escape routes for fish during seining. However, The Platform was ab to effectively sample through woody vegetation during the study producin accurate results. Due to its increased sampling speed, The Platform was also able to sample a greater volume of water than beach seining over the same period of time. The Kodiak trawl was able to sample a greater water volume, but was much less manoeuvrable, was not able to sample complex habitats, and caught fewer fish per unit of water

Overall, the team found that The Platform was able to adequately mple fish across habitat types that would normally require multiple types for standardised and comparable data across habitats, without the bias associated with using different gears. In addition, because it can collect more individuals in the same amount of time as both trawls and seines, it may prove to be more effective for detecting species that are less common, such as those that are threatened or endangered.

\section{DEVELOPING THE PROTOTYP}

The Platform is a prototype and is still undergoing testing and further development. Future and ongoing Investigations include refining the and size estimation directly fontication box video, as well as expanding The Platform's depth range Modifications of the net attachment angle and net height could extend the sampling depth range, allowing for future research comparing The Platform with offshore techniques that sample deeper in the water column.

The Plattorm provides an effective, nove method for monitoring the spatial and temporal variability of various aquatic habitats. It has the potential to not only evaluate the anthropogenic impacts on aquatic ecosystems, but also to assess the effectiveness of restoration efforts and monitor the effects of management activities on fish communties. This, in

\section{Behind the Research

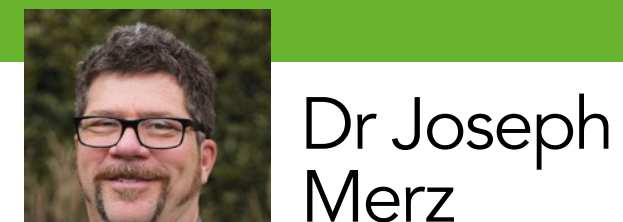 9 \\ Mr Jesse \\ Anderson}

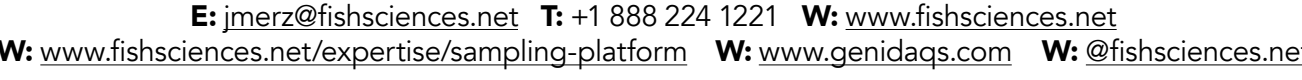

Research Objectives

Cramer Fish Sciences' mission is to provide quality, expert science which supports wise policy decisions and advances the field of natural resource management. We collaboratively find innovative and practical solutions to fisheries, riparian, and aquatic ecology challenges.

\section{Detail}

\section{Address}

Joseph Merz, Cramer Fish Sciences,

$7525 \mathrm{NE}$ Ambassador Pl, Suite C,

Portland, OR 97220 USA

Bio

Dr Joseph Merz has over 28 years of experience working for state, city, instructor and fisheries ecologist. He has

extensive experience with habitat typing and implementing revolutionary

monitoring equipment and techniques, and has designed multiple habitat-

restoration projects.

\section{Funding}

The United States Department of the Interior, Bureau of Reclamation, and the
California Department of Water Resources

\section{Collaborators}

- Cramer Fish Sciences Lab

- Research and Development Lab

- Genidaqs Molecular Biology an

Genetics Lab

ce and Restoration Lab - United States Bureau of Reclamation

\section{References}

Merz, JE, Anderson, JT, Wiesenfeld, J, Zeug, SC, (2021) Comparison of three sampling methods for small. org/10.1007/s10661-021-09027-9

Merz, JE, Camp, MJ, Simonis, JL, Thorpe, W, (2021) A new method for standardizing inland fish community surveys: characterizing habitat features controlling small-bodied fish species, abundance, and size distributions in a highly modified estuary. Frontiers in Environmental Science, 9 (698210). doi.org/10.3389/fenvs.2021.698210

Merz, JE, (2017), Single-Platform Integrated Aquatic Species and Habitat Sampling System US20160003713A1. patents. google.com/patent/US20160003713A1/en

\section{CRAMER}

FISH SCIENCES

\section{Personal Response}

\section{Do you think The Platform could become the new} standard for fish monitoring?

II While no one method can sample all habitat and fish community conditions, I strongly believe The Platform's ability to more accurately relate environmental data and fish species to a specific moment and place is a direction an exciting new fisheries science and management tool for evaluating anthropogenic impacts on ecosystems, assessing estuary restoration effectiveness, and monitoring the effects of management activities on fish communities in a more informative ecological contex compared to more conventional sampling methods. believe our results are timely given the increased interest in reducing physica handling of fishes, which may cause stress, harm, and mortality - all undesirable side effects 